\title{
EDITORIAL
}

\section{Psychedelic drugs as new tools in psychiatric therapeutics}

\author{
Eduardo E. Schenberg (iD) \\ Instituto Phaneros, São Paulo, SP, Brazil.
}

It is a "gratuitous grace," which is neither necessary nor sufficient for salvation, but which, if properly used, can be enormously helpful to those who have received it. (Aldous Huxley)

Given that, according to World Health Organization projections, mental health will be one of the most critical areas this century, developing new psychiatric treatments is urgent. Recent advances with psilocybin in severe depression treatment and 3,4-methylenedioxymethamphetamine (MDMA) in post-traumatic stress disorder (PTSD) treatment have led to their being granted "breakthrough therapy status" by the U.S. Food and Drug
Administration. ${ }^{1}$ In this issue we report the successful results of MDMA-assisted psychotherapy for Brazilian patients with severe PTSD (summarized in Figure 1). ${ }^{2}$ This approach deserves attention from mental health professionals nationwide, since the prevalence of this disorder, which is already high, is likely to increase as COVID-19 infections and fatalities escalate in Brazil. ${ }^{3}$

Psychiatry's history with these drugs began around 1953, when psychiatrist Humphry Osmond handed a glass of water containing $400 \mathrm{mg}$ of mescaline to Aldous Huxley, worrying he might drive the famous writer mad. In 1956 their continuous intellectual exchange led Osmond to craft the neologism 'psychedelic' (from the Greek for

\section{MDMA-assisted psychotherapy in Brazilian PTSD patients}

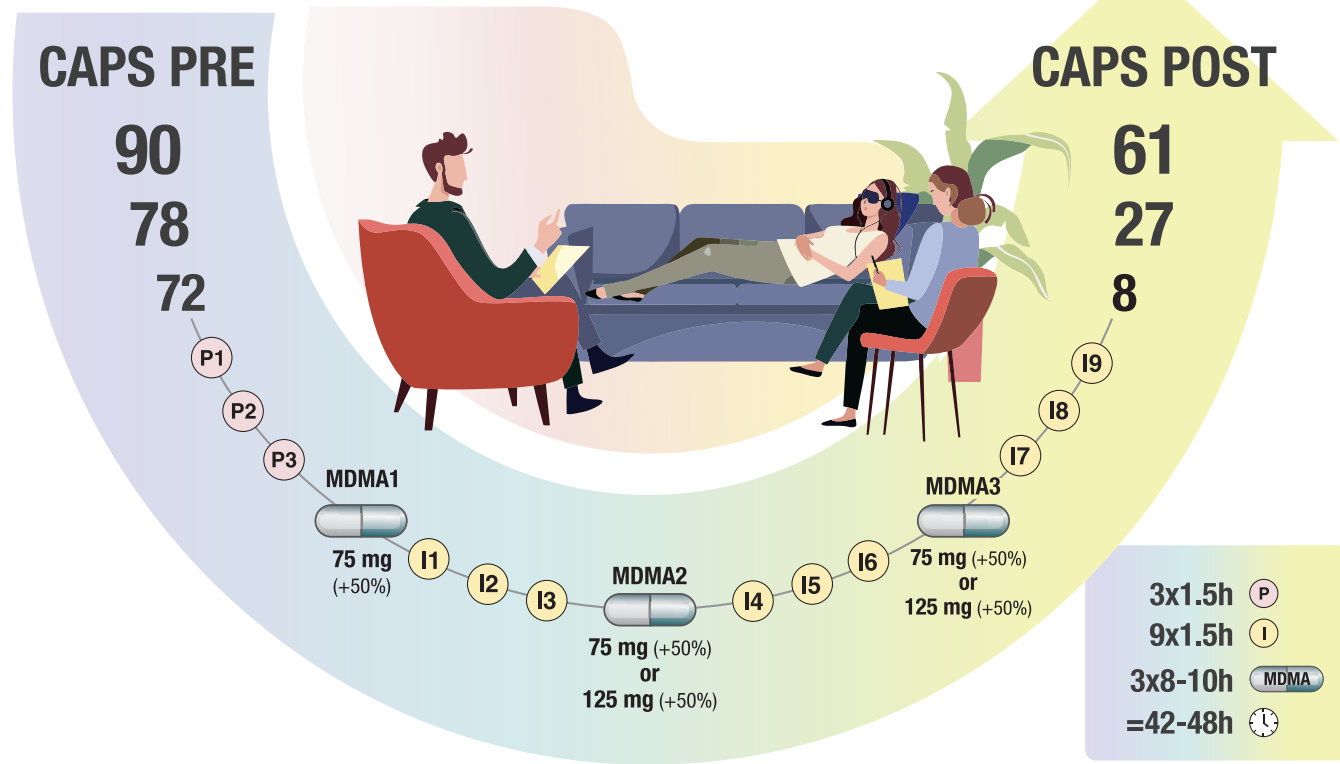

Figure 1 Schematic representation of MDMA-assisted psychotherapy treatment setting and protocol. At the bottom, the sequence of 15 weekly psychotherapy sessions is represented, including three preparatory $(P)$ sessions, three MDMA sessions, and nine integrative (I) sessions. The primary outcomes were pre-and post-treatment scores on the clinicianadministered PTSD scale (CAPS), which are depicted at upper left and upper right, respectively. All three patients had clinically significant improvements and few adverse events. Details on the methods and results are reported by Jardim et al. in this issue. $^{2}$

Correspondence: Eduardo E. Schenberg,

E-mail: eduardoschenberg @gmail.com

Submitted May 25 2020, accepted May 25 2020, Epub Jun 222020.
How to cite this article: Schenberg EE. Psychedelic drugs as new tools in psychiatric therapeutics. Braz J Psychiatry. 2021;43: 121-122. http://dx.doi.org/10.1590/1516-4446-2020-0012 
"mind manifesting"), reasoning that: "The name should have a clear meaning, be reasonably easy to spell and pronounce and not be too like some other name. [...] Psychedelic seems unambiguous, not loaded with old associations and clear." At that time both men had also experimented with LSD, which was invented in 1938 by Albert Hofmann, who discovered its psychoactivity in 1943.,5 These occurrences predate the discovery of serotonin in the mammalian brain, as well as the use of chlorpromazine, iproniazid and lithium, commonly considered the first modern psychiatric drugs. Yet LSD was tested for different conditions, most famously alcoholism, in the 1950s and had an important role in the broad acceptance of chemical neurotransmission due to its remarkable long-lasting effects in minute amounts (dozens to hundreds of micrograms). ${ }^{4,5}$

In the 1980s, LSD was used in studies that established the existence of different serotonin receptors, 5HT-1 and $5 \mathrm{HT}-2$, demonstrating that the psychoactivity of these drugs was not due to toxic effects in the brain, as previously speculated, but rather to precise activation of naturally occurring proteins in neuronal membranes. ${ }^{1,5,6}$ Four decades later, noninvasive and minimally invasive neuroimaging technology, such as M/EEG, fMRI and PET, has allowed human brain activity to be decoded during the acute action of psychedelics. The results have shown, for example, that psilocybin binds to $5 \mathrm{HT}-2 \mathrm{~A}$ receptors, which are most densely expressed in the apical dendrites of pyramidal neurons in layer $\mathrm{V}$ of the human neocortex, and increases their firing rates. This reaction cascades through the cortex, inducing temporary desynchronization of brain rhythms, the subjective effects of which statistically correlate with receptor occupancy and spectral changes in specific networks. ${ }^{1,5,6}$

This refined neurophysiological understanding of their acute pharmacological mechanisms of action, from cellular to systemic levels, is remarkable because, unlike most psychiatric drugs, psychedelics are not intended for chronic use. Instead, psilocybin and MDMA, which increase serotonin, noradrenaline and dopamine levels, have been shown to possess exceptional fast-acting therapeutic potential when administered on very few occasions in association with psychotherapy. ${ }^{1,5,6}$ Both drugs are currently being tested for dependence issues, and published studies show promising results for end-of-life anxiety in cancer patients, smoking-cessation interventions, social anxiety in autistic adults and, most importantly, depression and PTSD. ${ }^{1,5,6}$ Acute neuroimaging of the action of these drugs, which are employed clinically in only one to three sessions per patient, has enormous translational value for future psychiatric clinical practice since psychedelicassisted psychotherapy is conceptually different from current stand-alone drug treatments. ${ }^{1}$ Non-daily administration can reduce adverse effects, including withdrawal symptoms, which increase with prolonged daily use of psychiatric drugs. Administering psychedelics under medical and/or psychological supervision also limits or completely eliminates the risk of drug diversion and abuse, not to mention addiction risk, which is very low for psychedelic substances, especially when administered on a few occasions under medical supervision. ${ }^{1,5,6}$
During our MDMA study in 2018, the Brazilian authority responsible for all activities involving controlled substances, the Brazilian Health Surveillance Agency (ANVISA), also granted us authorization (AEP 012/2018) to use psilocybin in a study to treat severe depression, which is also highly prevalent in the country. However, the research protocol was rejected twice by an ethics review board, which incorrectly stated that these substances could not be used in scientific research. Since ANVISA does have clear rules regarding such research (Portaria $344),{ }^{7}$ an administrative suit was filed and ethical approval was obtained, albeit with a delay of over one year. ANVISA has also recognized the importance of facilitating research with controlled substances, proposing new norms in December, 2018 (Consulta Pública 587) ${ }^{8}$ and passing a resolution in April, 2020 (Resolução da Diretoria Colegiada $367)^{9}$ to keep this research unimpeded. Such steps can facilitate the approval of treatments involving psychedelics in Brazil. The safety and efficacy of MDMA is being tested in an ongoing randomized, multisite, double-blind international Phase 3 study. ${ }^{5}$

Since depression and PTSD are expected to increase and cause serious mental health and economic problems, these advances could be a welcome innovation for Brazilian psychiatry. Therefore, it is time for mental health professionals to seriously consider whether psychedelics, although still not sufficient, may become necessary.

\section{Disclosure}

The author reports no conflicts of interest.

\section{References}

1 Reiff CM, Richman EE, Nemeroff CB, Carpenter LL, Widge AS, Rodrigues $\mathrm{Cl}$, et al. Psychedelics and psychedelic-assisted psychotherapy. Am J Psychiatry. 2020;177:391-410.

2 Jardim A, Jardim D, Chaves BR, Steglich M, Ot'alora G M, Mithoefer $\mathrm{MC}$, et al. 3,4-methylenedioxymethamphetamine (MDMA)-assisted psychotherapy for victims of sexual abuse with severe post-traumatic stress disorder: an open label pilot study in Brazil. Braz J Psychiatry. 2021;43:181-5

3 Ornell F, Schuch JB, Sordi AO, Kessler FH. "Pandemic fear" and COVID-19: mental health burden and strategies. Braz J Psychiatry. 2020;42:232-5.

4 Bisbee CC, Bisbee P, Dyck E, Farrel P, Sexton J, Spisak JW. Psychedelic prophets. The letters of Aldous Huxley and Humphry Osmond. London: McGill-Queen's Press.

5 Nichols DE. Psychedelics. Pharmacol Rev. 2016;68:264-355.

6 Nutt D, Erritzoe D, Carhart-Harris R. Psychedelic psychiatry's brave new world. Cell. 2020;181:24-8.

7 Brasil, Ministério da Saúde, Secretaria de Vigilância em SaúdePortaria $\mathrm{n}^{\circ}$ 344, de 12 de maio de 1998 [Internet]. [cited 2020 May 24]. https://bvsms.saude.gov.br/bvs/saudelegis/svs/1998/prt0344_12_05_ 1998_rep.html

8 Agência Nacional de Vigilância Sanitária (ANVISA). Consulta Pública $\mathrm{n}^{\circ}$ 587, de 24 de dezembro de 2018 [Internet]. [cited 2020 May 24]. http://portal.anvisa.gov.br/documents/10181/5210712/\%281\%29CON SULTA + P\%C3\%9ABLICA + N\%C2\%BA + 587 + COCIC.pdf/e0d147 13-8673-41e0-bfc4-b4ab82665ec1

9 Agência Nacional de Vigilância Sanitária (ANVISA). Resolução de Diretoria Colegiada - RDC ${ }^{\circ} 367$, de 6 de abril de 2020 [Internet]. [cited 2020 May 24]. http://portal.anvisa.gov.br/documents/10181/5210712/ RDC_367_2020_.pdf/5dfd0fa7-cf99-4bd4-837c-d3baf098a191 